\title{
Letter to the editor concerning "Demographics, presentation and symptoms of patients with Klippel-Feil syndrome: analysis of a global patient-reported registry" by Nouri et al. [Eur Spine J; (2019) 28(10): 2257-2265]
}

\author{
Bailong $\mathrm{Hu}^{1}$ (1) $\cdot$ Haiyan $\mathrm{Zhou}^{2} \cdot$ Xiaohua Zou ${ }^{1}$
}

Received: 10 October 2019 / Revised: 10 October 2019 / Accepted: 17 November 2019 / Published online: 26 November 2019

(c) Springer-Verlag GmbH Germany, part of Springer Nature 2019

To the Editor:

In a recent study, Nouri et al. [1] have reported the demographics, presentation, and symptoms of patients with Klippel Feil Syndrome (KFS), and the authors showed that associated comorbidities including Sprengel deformity may be more common in KFS patients with multilevel cervical fusions. We highly appreciate their work on this important topic. However, we found a flaw in the statistical analysis that calls the results into question.

According to the article, the missing ribs rate between the single-level fusion group and multiple-level fusion group was analyzed by the Chi-squared test, and the $P$ value was 0.046. However, from Table 4 of the article, we found that there were more than $20 \%$ of cells with an expected value of less than 5 for the "missing ribs rate." In this case, we should use Fisher' s exact test instead of Chi-square test [2]. We calculated using Fisher' s exact test, and the $P$ value was 0.054 , which means the missing ribs rate between the two groups was not statistically significant. Thus, we suggest the authors check and analyze the data again in order to present the appropriate conclusion.

Bailong $\mathrm{Hu}$

375896605@qq.com

$\bowtie$ Xiaohua Zou

409017612@qq.com

1 Department of Anesthesiology, The Affiliated Hospital of Guizhou Medical University, No. 28 Guiyi Street, Yunyan District 550004, Guiyang, China

2 Department of Clinical Research Centre, The Affiliated Hospital of Guizhou Medical University, No. 28 Guiyi Street, Yunyan District 550004, Guiyang, China
Funding None.

\section{Compliance with ethical standards}

Conflict of interest The authors declare that they have no conflict of interest.

\section{References}

1. Nouri A, Patel K, Evans H et al (2019) Demographics, presentation and symptoms of patients with Klippel-Feil syndrome: analysis of a global patient-reported registry. Eur Spine J 28(10):2257-2265

2. Armitage P, Berry G, Matthews JN (2002) Statistical methods in medical research, 4th edn. Blackwell Publishing, Malden, pp 134-137

Publisher's Note Springer Nature remains neutral with regard to jurisdictional claims in published maps and institutional affiliations. 